\title{
Antropomarketing Holístico: Naturaleza y Fundamentos
}

\author{
Prof. Carlos CAVANI GRAU
}

La primera impresión que usted podría tener de la noción Antropomarketing holístico sería de curiosidad, o de perplejidad, o solo de sorpresa por el sentido de la palabra: no solo es Antropomarketing sino que además es holístico. Entonces, interesado lector, la intención de este artículo no es confundirlo más, sino intentar explicar cuál es su verdadera naturaleza y los fundamentos que le dan contenido a una nueva disciplina del marketing en las actuales circunstancias.

En primer lugar es importante mencionar que laAntropología es una ciencia social fundamental y vigente en tanto se orienta al estudio del hombre. Su etimología revela que el antrophos denomina al hombre y logos es conocimiento. Entonces el conocimiento del hombre o el tratado del hombre es una ciencia social trascendental y con una alta responsabilidad para comprender científicamente los 5 millones de años que registra la evolución de la especie humana, desde los primeros homínidos hasta el homosapiens sapiens que es el producto contemporáneo de un accidentado y prolongado proceso evolutivo. Es evidente que los primeros homínidos registrados por importantes estudios arqueológicos y antropológicos, como el pitecántropus erectus, los hombres de Neanderthal, los homínidos de Java o los primeros homohabilis fueron eminentemente cazadores, con una clara división de trabajo y responsabilidad en la constitución y supervivencia de los primeros clanes u organizaciones nómades. Así como las mujeres fueron paulatinamente especializándose en las tareas de recolección, selección, y preservación de los productos de supervivencia, los alimentos, así como al cuidado de los hijos del clan y su supervivencia como especie. La permanencia consuetudinaria de la mujer, eventualmente, en sus refugios precarios fue creando en ellas un conjunto de patrones antropográficos como la comunicación, la observación de los productos de supervivencia, y otras especialidades paulatinamente más complejas.

Camilo Herrera sostiene que el hombre ha sido cazador y la mujer recolectora por más de 5.000 años y los últimos 100 años de transformaciones no han podido cambiar ese proceso; lo han modificado. El hombre puede estar en casa pero 
sigue siendo clásico en su forma de vestir, y otros patrones comportamentales, porque como cazador no quiere ser llamativo; mientras que la mujer, al salir al mundo laboral su principal arma de caza es ser atractiva, como lo hacía anteriormente para llamar la atención del cazador, en la búsqueda paciente pero perseverante de seguridad; pero aún son muchas más las mujeres trabajadoras que actualmente miran la fecha de vencimiento de los productos, que es una inclinación antropológica, que los hombres que comienzan a hacer el mercado para la casa, lo cual constituye otro patrón indudablemente antropológico. Es muy probable que a los jóvenes adultos aun no les guste comprar productos de primera necesidad o abarrotes en los supermercados o mercadillos -esa función se la dejan a los padres- pero el modelo paterno, tarde o temprano, los influenciará.

Es sorprendente que en las carteras que portan la mayoría de mujeres haya muchos efectos personales, algunos realmente inverosímiles, y cuando suena el timbre de sus celulares digitales abran sus bolsos o carteras para encontrar con dificultad estos aparatos en medio de todas las cosas que ellas portan. En las grandes migraciones nómades, las mujeres cargaban a los hijos, los alimentos, y las pieles, ubicándose en la retaguardia.

A diferencia de los hombres que en su gran mayoría no portan bolsos y se conducen con escasos efectos en sus bolsillos, entre estos las llaves de sus casas o sus vehículos o solo sus documentos personales. Respecto a las grandes migraciones, los hombres portaban sus armas, y sus herramientas, ubicándose en la vanguardia, listos a rechazar cualquier ataque de animales o de otras comunidades nómades.

Así, el mercadeo y el trade marketing tienen que entrar en los terrenos pedregosos de aceptar que los seres humanos tenemos una historia que guía muchos de nuestros comportamientos; a esto algunos lo han querido llamar instintos o incluso neuromarketing, pero no es otra cosa que el sentido común de reconocer que somos parte de un proceso antropológico e histórico.

Es casi imposible encontrar un comportamiento del consumidor que no tenga vínculos antropológicos e históricos. Pero lo que ocurre es que nuestra capacidad de adaptación es tan veloz que dejamos atrás inventos fundamentales simplemente porque hay algo mejor o más moderno; pero en el momento más inesperado estamos usando el celular de última generación para escribir notas como hacemos en un cuaderno y estamos chateando como si pusiéramos telegramas. Nos es imposible desvincularnos de los procesos anteriores, porque toda solución parte de una necesidad insatisfecha o un deseo insatisfecho parcial o completamente. Claro que esto sucede con los consumidores de vanguardia en mayor medida que los consumidores intermedios o mucho más que los 
rezagados. Por ejemplo la empresa Apple innova permanentemente y lanza sus nuevos productos con shows mundiales como el reciente Ipad y congrega a nivel global a sus fans tecnológicos, que son consumidores de vanguardia ávidos de tener en sus manos el nuevo "esperpento tecnológico", y que se amanecen en la acera esperando que las tiendas de productos electrónicos se abran para abalanzarse y adquirir uno, como el Ipad que ha sumado en esta nueva versión otras innovaciones respecto al anterior, que solo fue lanzado el año pasado.

\section{LA NOCIÓN HOLÍSTICA}

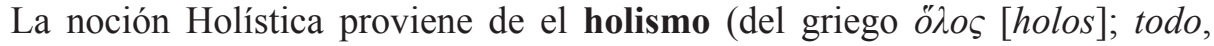
entero, total) es la idea de que todas las propiedades de un sistema dado, (por ejemplo, biológico, químico, social, económico, mental o lingüístico) no pueden ser determinados o explicados por las partes que los componen por sí solas. El sistema como un todo determina cómo se comportan las partes. Como adjetivo, holística significa una concepción basada en la integración total frente a un concepto o situación.

El principio general del holismo fue resumido concisamente por Aristóteles en la metafísica (libros que escribió después de la física): "El todo es mayor que la suma de sus partes".

Se puede definir como el tratamiento de un tema que implica todos sus componentes, con sus relaciones invisibles por los cinco sentidos, pero evidentes igualmente. Se usa como una tercera vía o un nuevo enfoque a un problema. El holismo enfatiza la importancia del todo, que es más grande que la suma de las partes (propiedad de sinergia), y da importancia a la interdependencia de éstas. Trata de presentarse directamente como un axioma para el nuevo planteamiento que se proponga resolver y a veces no es expuesto como una hipótesis. Este es su principal problema de validación, al ver si tiene las propiedades del método científico.

La holística es aquello perteneciente al holismo, una tendencia o corriente que analiza los eventos desde el punto de vista de las múltiples interacciones que los caracterizan. El holismo supone que todas las propiedades de un sistema no pueden ser determinadas o explicadas como la suma de sus componentes. En otras palabras, el holismo considera que el sistema completo se comporta de un modo distinto que la suma de sus partes. 


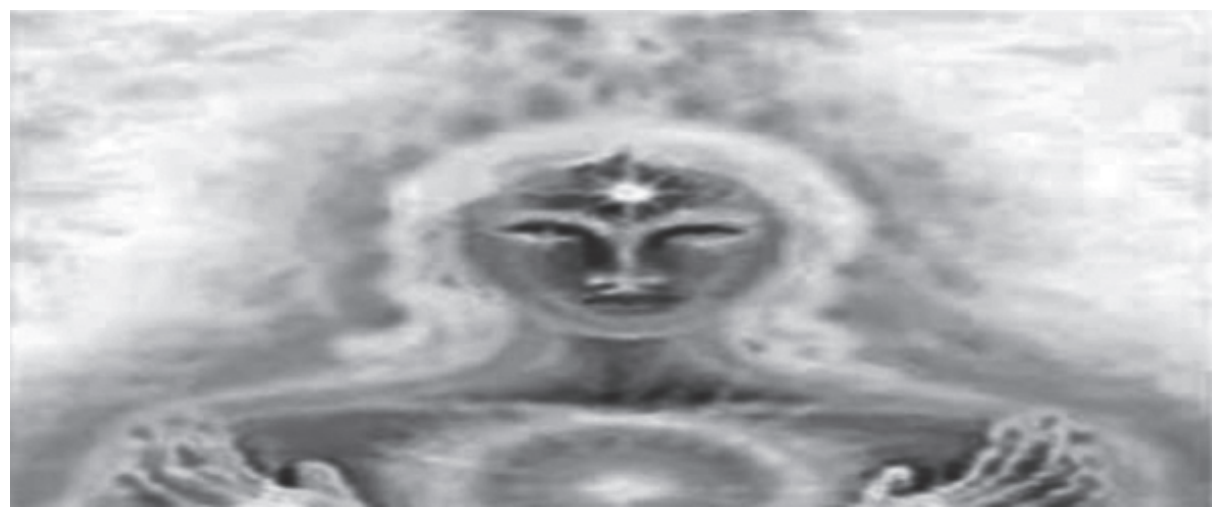

Una representación gráfica del Holismo

De esta forma, el holismo resalta la importancia del todo como algo que trasciende a la suma de las partes, destacando la importancia de la interdependencia de éstas. Cabe mencionar que el holos (un término griego que significa "todo" o "entero") alude a contextos y complejidades que entran en relación, ya que es dinámico.

Para la comprensión holística, el todo y cada una de las partes se encuentran ligadas con interacciones constantes. Por eso cada acontecer está relacionado con otros acontecimientos, que producen entre sí nuevas relaciones y eventos en un proceso que compromete el todo.

La comprensión de los procesos y las situaciones debe tener lugar desde el propio holos, ya que en su dinamismo, surge una nueva sinergia, ocurren nuevas relaciones y se generan nuevos acontecimientos. Por lo tanto, el todo es lo determinante, aun cuando este reconocimiento no impide que se analice cada caso en particular.

La perspectiva holística implica una superación de los paradigmas para propiciar la figura del sintagma, entendida como una integración de paradigmas. Una actitud sintagmática supone la convergencia de diversas perspectivas, lo que sólo puede lograrse con criterios holísticos.

\section{FUNDAMENTOS}

Por lo tanto el Antropomarketing Holístico constituye un todo, un sistema compuesto por un conjunto de elementos que son a su vez sus propios fundamentos endógenos como las necesidades y los deseos del ser humano, los patrones comportamentales como la personalidad, motivaciones y las actitudes, los patrones cognitivos como el aprendizaje. Otros patrones antropográficos 
como los estilos de vida, y patrones neurales como las sensaciones y percepciones. Así como los patrones exógenos como la Cultura, la Familia, los Grupos de referencia y las clases sociales. Estas nociones las trataremos en un segundo ensayo.

\section{LAS OTRAS FUENTES DEL MARKETING}

Las otras fuentes teóricas del marketing contemporáneo como la antropología, son también la economía, la sociología y la psicología individual y social. La Economía como ciencia social no solo es la que explica la utilización de los recursos escasos para el desarrollo sustentable del proceso económico de los pueblos sino el fundamento poderoso del intercambio basado en la ley de la oferta y la demanda. Adam Smith, extraordinario precursor de la economía sostuvo en su texto "La Riqueza de las naciones" (The wealth of the Nations, 1776) que las sociedades no son solidarias y altruista per se, sino que la oferta y la demanda generan las condiciones para el funcionamiento del proceso económico.

Pero la correspondencia entre el marketing y la economía reside en que el primero es capaz -orientado correctamente por sus operadores- de estimular los términos de intercambio a través de un producto adecuado, un precio razonable, una plaza o canal de distribución conveniente y una promoción oportuna.

Otros aportes de la economía al marketing son el concepto de homo economicus, aquel que siempre consumirá el producto que le de más utilidad en función del precio, pero que luego de sufragar sus gastos elementales es capaz de exigirse al máximo para construir un ahorro que le permita cierta gratificación por el sacrificio realizado para sobrevivir. Los economistas lo llaman los costos marginales. La ley de Lancaster que sostiene no es el producto como tal el que genera la satisfacción sino los atributos que lo caracterizan. Rovira y Dubois dicen que no es la pasta de dientes en si misma donde está el origen de la satisfacción (o de la insatisfacción) del consumidor sino en el hecho que este producto procure un mejor aliento, protección contra la caries, los dientes más blancos, etc.

Las elecciones de los individuos se basan en las características y subcaracteristicas de los productos antes que en las entidades-productos.

Por lo que reiteramos que existe una concepción económica del marketing que termina por reconocer que contemporáneamente hablando, la disciplina es probable y posible en una economía de mercado y cuando la oferta supera a la demanda. Es que el marketing es capaz de estimular los términos 
microeconómicos del intercambio, la oferta y la demanda. Algún autor reconoce al marketing como la ciencia del intercambio.

En términos del Proceso económico, las fases sucesivas de Extracción, Transformación, Distribución y Consumo son claves para comprender que el objetivo fundamental del proceso es la creación del valor agregado, que el papel del marketing es condicionante en las primeras etapas y determinante en la etapa de la distribución, en la que es capaz de construir su propia cadena de valor basado en la satisfacción irrestricta de las necesidades y deseos del consumidor. Nos referimos a las utilidades de forma, de lugar, de tiempo, y de posesión.

\section{CONSUMO}

El consumo es una actividad humana omnipresente, porque se representa en una constelación de actividades humanas.

Es la fase en la que el cliente consumidor ha obtenido el producto y lo ha usado o consumido o lo ha desechado.

¿Por qué compra la gente?. Esta pregunta sigue devaneando los sesos de los especialistas quienes continúan respondiéndola para nuestra felicidad o mayor confusión desde diferentes ópticas: la económica, la sociológica, la antropológica o la conductual. Los mercadólogos cual pragmáticos observadores y decisores de las campañas comerciales las adaptan dramáticamente a los designios de los consumidores. Pero, ¿cómo han cambiado los consumidores peruanos en los últimos años? Cualquier respuesta inmediatista se estrellaría con la realidad. Hasta hace algunos años -utilizando un argot marketero- eran "lornas" y ahora se han convertido en verdaderos "tiburones", por ansiosos, recelosos, desconfiados, desafiantes y compulsivos.

Muy a nuestro pesar dejemos este estilo coloquial para intentar, ansioso lector, ofrecerle algunas explicaciones a esta gran pregunta: ¿por qué compra la gente? Las necesidades y los deseos humanos en pos de satisfactores múltiples e indistintos están en el centro de la Motivación humana. ¿Por qué compra la gente? -curiosamente el título de uno de los videos precursores del Marketing más populares de la década del 70-, es una pregunta clave para entender las razones fundamentales de las decisiones de compra de las personas que por lo general están orientadas a un consumo que Henry Assael (2005) define como un acto omnipresente tan vital que cuando dormimos también consumimos... oxígeno y tan superfluo o banal como comprar un Ferrari de 250,000 dólares. Y si científicamente respirar es un acto de consumo para vivir, comprar el Ferrari solamente constituiría un hito extraordinario... en el ego de su cliente propietario. 
Aun si fuera de esta naturaleza, vital o banal, las personas-consumidoras tienen millones de razones para comprar como millones de razones para no hacerlo, y cuanto más estudiamos tales razones más ignoramos las verdaderas causas que los llevaron a esas decisiones de compra. Del conjunto de teorías explicativas de las razones de compra del consumidor como la teoría económica, la teoría sociológica, la teoría del aprendizaje, la teoría conductual o psicológica; esta última nos parece importante -sin menoscabo de las anteriores- porque se funda en la existencia de actitudes cognitivas o racionales, emotivas, afectivas e inconscientes, todas ellas razones relativas, porque las actitudes no son patrones comportamentales fácilmente observables(Chaparro,2008).Las necesidades fisiológicas y de seguridad representan poderosas necesidades innatas como el hambre o el sueño o la comunicación, las razones emotivas son de naturaleza psicógena y reactivas a eventos emocionales de impacto como el nacimiento de un bebe y las motivaciones afectivas también de naturaleza psicógena advierten relaciones de pertenencia de profunda naturaleza de afiliación como la inclinación gregaria. Las razones inconscientes nos conducen a adquirir satisfactores inéditos, para nuestra conducta normal de compra por la presión de las ventas por impulso (degustaciones, óbolos inopinados, colectas públicas, etc.)

\begin{tabular}{l}
\hline ÉNFASIS SOCIAL I \\
Al Marketing empresarial e institucional no solo le basta orientarse a \\
la satisfacción de las necesidades humanas que son de naturaleza innata \\
y sentida en la aseveración de Gist (1990), sino fundamentalmente en \\
la creación y recreación de un nuevo estándar de necesidades humanas \\
delineadas por los patrones comportamentales y la influencia del entorno, \\
los deseos humanos. \\
Entonces es un mito del marketing aquel que sostiene que crea necesidades \\
sin explicar que tipo de necesidades son. En realidad las necesidades \\
-para ser rigurosos- son estados de carencia innatos a la especie humana, \\
relativamente diferentes a los deseos que son formas de necesidades latentesy \\
adquiridas cifradas en satisfactores específicosy no de naturaleza genérica: \\
preferimos ocasionalmente un vaso de cerveza helada que un vaso de agua \\
fresca. O como afirmaba el Profesor Arellano estamos acostumbrados a \\
tomar todo el año, a despecho de las estaciones, agua helada, sobre todo en \\
Lima.
\end{tabular}

Repasemos las interpretaciones de las teorías de consumo, señalando que la teoría económica del consumo está representada por el concepto de "homo economicus", aquel que siempre consumirá el producto que le de más utilidad en función del precio, el hombre económico que luego de sufragar sus gastos fundamentales de sobrevivencia orienta el saldo económico que le sobra a 
decisiones de consumo más bien placenteras, como premiándose por los estados de privación experimentadas por los individuos en el contexto de una sociedad de consumo. Los economistas llaman a estas decisiones los costos marginales, que grafican a la comunidad de consumidores tomando decisiones de consumo austeras, sin brillo en un escenario económico en el que la demanda supera a la oferta.

Reciclaje: es el proceso que consiste en la reutilización de un producto que ha sido desechado y convertido en materia prima para iniciar nuevamente el proceso productivo.

Ejemplo: La reutilización de las aguas servidas o rehúso de los desperdicios líquidos urbanos.

Cuenta con el siguiente proceso: Lagunas de Estabilización:

$\begin{array}{llll}1 & 2 & 3 & 4\end{array}$

Colector de aguas residuales, Laguna Primaria Laguna secundaria, Efluente de aguas con tratamiento Secundario (17 días dura el Proceso) van a regadíos.

En la laguna primaria y secundaria (sedimentary ponds o pozos de bioestabilización) el agua sufre una suerte de digestión en la que participan algas, bacterias, encimas y luz solar).

Como resultado tenemos aguas semipotables, no aptas para el consumo humano pero sí para fines de regadío.

La Sociología constituye como ciencia social el estudio de las relaciones interpersonales y su vinculación con el entorno.

La teoría sociológica que se funda en la preminencia de los grupos sociales sobre el individuo, una suerte de hermano mayor que circunda, influencia y lo presiona a la búsqueda, indagación y compra de satisfactores que a la postre solo fortalecerán el espíritu gregario sobre el espíritu individual. El individuo solo desea pertenecer al grupo de referencia y satisfacer una profunda necesidad de refugio social.

La teoría del aprendizaje basada en la certeza del positivismo de las experiencias acumuladas a través del tiempo por sobre la obtención de nuevos conocimientos y experiencias de vida, de consumo. 
Y en atención a las necesidades, Abraham Maslow, a través de la Teoría de las Necesidades o Pirámide de las Necesidades identifica dos grandes grupos de necesidades:

1- Necesidades Primarias o Innatas (llamadas también, de mantenimiento o deficitarias).

2- Necesidades Secundarias o adquiridas (llamadas también de crecimiento o meta desarrollo o psicógenas)

Las necesidades primarias son las fisiológicas y de seguridad.

1a) Fisiológicas: están relacionadas a las necesidades de supervivencia: Como alimentación, vestido, vivienda, maternidad, sexo.

1b) Seguridad: están relacionadas a tener seguridad y orden: Tener orden en la vida, vivir libre de riesgos, tener seguridad tanto a nivel físico como emocional. En la concepción de Hofstede (Stephen Robbins 1998) una forma de vida alejada de la inseguridad con un refugio asegurado. Expresado asimismo por un fuerte instinto de supervivencia. Las necesidades secundarias o adquiridas (crecimiento o meta desarrollo).

1c) Afiliación o sociales:

Amor, aprecio, comprensión, cariño y pertenencia a grupos (proporcionan también sentido de seguridad al individuo). Asociación a clubes, agrupaciones civiles, grupos de estudio.

2a) Estima o Reconocimiento:

Un tributo de Maslow al extraordinario aporte de Sigmund Freud (1932), respecto al desarrollo de la personalidad humana expuesta a través del Ibíd. o Id, ego, y superego, nociones señeras y complejas planteadas por el creador del Psicoanálisis. El ego cifrado en el orgullo propio y expresado en múltiples formas por las personas como la consecución de un status, o un rol societario, niveles de prestigio e imagen ante otros grupos de referencia.

2b) Autorrealización o auto superación:

Es el grado más alto de la Jerarquía de las Necesidades humanas, donde en teoría, la persona ha satisfizo todas sus necesidades. En teoría, porque a través de las necesidades de autorrealización aun busca mayores logros, mayores reconocimientos, o un mayor poder, parafraseando a David MacLelland (1970). Otra lectura de estas necesidades representa al individuo orientado a trascender, dejar huella, dejar un legado, expresar sus ideas y convicciones. La 
filantropía y la continua búsqueda de aporte a la sociedad podrían ser otra representación de la autorrealización.

De acuerdo a Abraham Maslow, cuando las necesidades de orden inferior son satisfechas, se van activando o generando en el individuo otro tipo de necesidades. Ejemplo: Si la persona cree que morirá de hambre, buscará incansablemente la forma de conseguir alimento (Necesidades Fisiológicas). Cuando ya logró conseguir alimento buscará la forma de asegurar ese alimento a través de la búsqueda de un trabajo seguro que le permitirá asegurar dicho alimento, etc.).Sin embargo, existen algunos detractores a esta teoría que postulan que no todos los individuos satisfacen sus necesidades en este orden, $o$ que inclusive, tienen las mismas necesidades. Ejemplo: Una persona de escasos de recursos económicos buscará la forma de poder conseguir alimento para buscar satisfacer sus necesidades de orden inferior. En contraposición con una persona solvente económicamente, posiblemente ya se encuentre en el más alto escalafón de esta Pirámide porque el dinero ya le haya permitido satisfacer todas sus necesidades anteriores.

La Psicología trata de la conducta del hombre, de sus experiencias íntimas, y de las relaciones entre ambas. También se ocupa de los órganos que ejercen influencia sobre la experiencia y el comportamiento y de las conexiones de estos con el ambiente. La relación de la Psicología con el marketing está vinculada a los temas de la conducta del consumidor y al posicionamiento, entendido como la conquista de la mente del consumidor. Trout y Ríes, legendarios maestros del marketing afirmaron en la década del setenta que el marketing no es una batalla de productos sino una batalla de percepciones. Dando un giro drástico en la evolución del marketing contemporáneo y obligando a los especialistas a volver sus ojos sobre las fuentes del marketing: los consumidores.

Es que la personalidad, los estilos de vida, las motivaciones, las actitudes, las sensaciones, las percepciones y los patrones cognitivos (aprendizaje) constituyen los patrones comportamentales relevantes -aunque no son los únicos- que delinean endógenamente el comportamiento del consumidor. Los modelos contemporáneos de la toma de decisiones de consumo como Nicosia, Shiffman,

Engel-Blackwell-Kollat rescatan el conjunto de patrones endógenos comportamentales así como los patrones exógenos de naturaleza social y antropográfica como la cultura, las clases sociales, los grupos de referencia y la familia. 